\title{
INICIATTVA PRIVADA Y POLÍTICA PÚBLICA EN EL DESARROLLO DE LA INDUSTRIA ELÉCTRICA EN ESPAÑA. LA HEGEMONÍA DE LA GESTIÓN PRIVADA, 1875-1950 *
}

FRANCESCA ANTOLÍN

Universitat de Barcelona

\section{RESUMEN}

Analizo la introducción de la electricidad en España (1875-1900) y la consolidación del sector (1900-1950), con énfasis en la gestión de recursos. El sector privado tomó la iniciativa. El Estado también participó desde los inicios, pero subsidiariamente, contribuyendo a la formación de un marco institucional y legal. Las empresas consolidaron monopolios locales, y actuaron coordinadamente como oligopolio frente a la Administración. Sus estrategias de producción y de precios, bajo una escasa regulación y con mercados protegidos, se orientaron a la maximización de beneficios a corto plazo. Por ello, el consumidor español no fue el mejor servido, y la electricidad sólo contribuyó moderadamente al crecimiento.

\section{ABSTRACT}

I study the introduction of electricity in Spain (1875-1900) and the consolidation of this industry (1900-1950), from a managerial perspective. The private sector took the lead. The State's participation was subsidiary, helping to create an institutional and legal framework. Firms became local monopolies, and acted jointed as an oligopoly in their relationships with the Administration. Under protected markets and little regulation, their production and pricing strategies aimed at short run profit maximization. As a result, the Spanish consumer was not well attended, and electricity contributed only mildly to growth.

\footnotetext{
* Agradezco los comentarios de dos evaluadores anónimos y la ayuda financiera del proyecto PB97-0875.

Revista de Historia Económica

Año XVII, Primavera-verano 1999, N. 2.
} 


\section{INTRODUCCIÓN}

La electricidad ha contribuido de forma sobresaliente al crecimiento de las economías industriales desde que, a principios del siglo $\mathrm{Xx}$, se dispuso de tecnología adecuada para su producción, suministro y utilización en gran escala y a precios competitivos ${ }^{1}$. Desde el lado de la oferta, aquella contribución puede venir limitada por condicionantes físicos, como la dotación y accesibilidad a recursos de energía primaria, o económicos, tales como las características del marco institucional en el que se gestionan los recursos, los objetivos que se fijen las empresas del sector y los medios aportados por éstas ${ }^{2}$. Atendiendo a los condicionantes económicos, podemos distinguir diversos modelos de gestión, que se han dado en distintos países y épocas, con resultados distintos en cada uno de ellos ${ }^{3}$. Esquematizando, podemos agruparlos en tres, según que su gestión sea privada, privada regulada o pública.

Cuando la gestión es privada, como ocurrió en la mayoría de países en los inicios de la industria eléctrica, y más concretamente, durante los setenta y cinco primeros años de su desarrollo en España, 1875-1950, la contribución de la electricidad al crecimiento económico se ve mediatizada por la configuración de monopolios naturales locales, que interfieren en la minimización de costes de producción y en la maximización de los beneficios sociales, requisitos ambos para un uso eficiente de los recursos del país. En este contexto la presencia de monopolios privados no regulados resulta especialmente distorsionadora, dado que en la gestión de los recursos eléctricos concurren todas las instancias previsibles de fallos de mercado, por lo que no es de esperar que sea efectiva la acción disciplinadora de los mecanismos de mercado ${ }^{4}$. En general, los costes del suministro que

${ }^{1}$ Aspectos de esta contribución son: aumentar el aprovechamiento de los recursos de energía primaria de un país; ser susceptible de utilización en prácticamente todos los procesos productivos; aumentar la eficiencia energética de los consumos; permitir, vía mejora en el rendimiento y sustitución de factores, fuertes incrementos de productividad; y, finalmente, originar nuevos bienes y servicios intermedios y finales (Landes, 1969, y Devine, 1983).

${ }^{2}$ El libro de Joskow y Schmalensee (1985) contiene una discusión en profundidad del impacto de las formas de gestión de los recursos eléctricos sobre la economía.

'Para una descripción sucinta de las formas de organización de los sectores eléctricos en los países más industrializados (E-7) véase Stoffaës (1994).

4 Las circunstancias de fallo de mercado que concurren en el suministro de electricidad, y que en teoría justifican la intervención del Estado para promover mecanismos alternativos de asignación de recursos, son: la configuración de monopolios naturales locales, las asimetrías en la información de los agentes económicos, la presencia de rentas de escasez y efectos externos, la característica de bien público de algunas facetas del suministro eléctrico $y$, 
soportan los empresarios del sector y los precios que paga el consumidor se mantienen artificialmente elevados, la oferta no se halla en condiciones de satisfacer la totalidad de la demanda potencial, la calidad y fiabilidad del suministro son bajas y las rentas generadas por esta nueva forma de energía son retenidas por los productores ${ }^{5}$.

Cuando la gestión de los recursos eléctricos es pública, los resultados esperados son distintos. Esta circunstancia se dio, también al principio de la industria, en el ámbito municipal, de forma mayoritaria en el Reino Unido y parcialmente en EEUU y en otros países de la Europa continental. Posteriormente la gestión pública fue ampliando su ámbito de actuación. Así, en EEUU una agencia pública se hizo cargo de la gestión de los recursos hidráulicos del río Tennessee en el contexto de las medidas reactivadoras puestas a punto por la Administración Federal durante la depresión de los años treinta. A la conclusión de la Segunda Guerra Mundial y con objetivos similares, los gobiernos del Reino Unido, Francia e Italia emprendieron la nacionalización y gestión de los sectores eléctricos de sus respectivos paises. En principio, bajo esta forma de gestión se extiende el suministro a los consumos y consumidores que habrían quedado excluidos según los cálculos de rentabilidad propios de la gestión privada, mejora la calidad y disminuye el precio cobrado al consumidor. Respecto a la eficiencia en la asignación de recursos se observa que en términos de costes, por un lado deben ser inferiores, porque pueden aprovecharse economías de escala en la distribución y mejorarse la coordinación entre producción y sumistro así como la planificación en el desarrollo de los recursos; si bien, por otro lado, el fácil acceso al presupuesto del estado de que gozan las empresas públicas puede desvanecer los incentivos a la minimización de costes, y la ineficiencia de ciertos vicios de gestión puede llevar a que aquéllos se disparen ${ }^{6}$. Otra peculiaridad de la gestión pública es que se abandonan fácilmente las consideraciones de mercado en la toma de deci-

finalmente, la posibilidad de situaciones de competencia destructiva por ausencia de equilibrios competitivos (Joskow y Schmalensee, 1985).

'Para estudios que comparan la gestión privada y pública, ya sea a nivel de empresa o según áreas de mercado, dentro de un mismo país, véase Meyer (1975), Pescatrice y Trapani (1980), Millward (1982), Foreman-Peck y Waterson (1985) y Emmons III (1989 y 1993).

${ }^{6}$ Por ello resulta difícil comparar el comportamiento, incluso teórico, de los costes bajo los dos modelos de gestión, privada y pública. Además, muchas de las ventajas potenciales de la gestión pública bajo la hipótesis del Estado benefactor quedan desdibujadas por componentes de economía política. Las empresas públicas tienen acceso a canales de financiación privilegiados, y esto va a favor de la reducción de costes, pero muchas veces 
siones de producción y suministro. Es frecuente que se renuncie a la eficiencia económica para atender a la justicia, la calidad de vida o la seguridad nacional, sirviéndose del enorme abanico de posibilidades que ofrece el sector para materializar objetivos genéricos de política económica ${ }^{7}$.

Cuando la responsabilidad pública sobre la gestión de los recursos eléctricos se ejerce a través de la regulación del sector privado, los resultados son mucho más aleatorios, y se puede alcanzar cualquier combinación de las virtudes y los vicios de los dos tipos extremos de gestión. Desde el inicio de la industria, los pliegos de condiciones de las concesiones de suministro otorgados por los gobiernos municipales a las empresas privadas constituyen un primer nivel de regulación. No obstante, la regulación que atiende a consideraciones de eficiencia es la de ámbito estatal, siendo el país pionero los EEUU con la creación en 1907 de la primera agencia estatal ${ }^{8}$. La gestión de los recursos eléctricos durante los gobiernos del general Franco se ajusta a este modelo y muestra uno de los posibles resultados del modelo de gestión pública indirecta. Para empezar, cabe resaltar que los objetivos de la regulación fueron complejos. Se trató de compaginar la satisfacción de los objetivos del oligopolio de empresas privadas configurado en el período anterior con los de la nueva Administración. Estos últimos consistieron en subordinar la eficiencia en la gestión de los recursos eléctricos a su contribución destacada a la política desarrollista, básicamente, facilitando grandes cantidades de energía a bajo precio. Paralelamente a la creación de empresas públicas para el aprovechamiento de recursos o áreas de mercado previamente desestimadas por la iniciativa privada, las innovaciones más destacadas consistieron en la concesión de

se decide subvencionar a determinados sectores productores de materias primas, como el carbón u otros inputs, y esto puede obligar a consumir factores caros, lo que aumenta costes.

${ }^{7}$ Los objetivos declarados de la intervención pública, cuando la Administración se hace responsable de la gestión del sector eléctrico, se orientan a mejorar la eficiencia del sector, pero pocas administraciones se resistieron a la tentación de utilizar el recibo de la luz para subvencionar consumos o categorías de consumidores determinados, para controlar la inflación o para aumentar la imposición a través del aumento de las tarifas eléctricas, acción más difusa y menos impopular que otras. El número 4 de la Revista del Instituto de Estudios Económicos (1991) recoge las polémicas de las últimas décadas, en los países de la CE y en los EEUU, sobre objetivos y medios de la intervención pública, referida a las estrategias de reprivatización y/o de reordenación de aquella intervención.

${ }^{8}$ El suministro de electricidad es un sector de actividad en el que tradicionalmente ha intervenido el Estado. Al principio, porque una de sus primeras aplicaciones, el alumbrado público, era competencia de las administraciones municipales. Posteriormente, y a medida que fueron surgiendo nuevas utilizaciones y que se desarrollaron el sector productor y el distribuidor, la intervención se justifica por la importancia estratégica del abastecimiento de energía en las economías industriales. 
subvenciones al aumento de capacidad y utilización de determinados energías primarias, junto con la introducción de un sistemas de precios y remuneraciones alejados de consideraciones de mercado. Dichas medidas produjeron graves distorsiones en la demanda y la producción eléctrica, escasez y racionamiento primero y sobreproducción y fuerte dependencia de combustibles de importación, más tarde. A un nivel más genérico, el abandono de criterios de mercado, junto con la utilización de la política energética con fines desarrollistas contribuyó, a su vez, a empeorar la eficiencia en términos de costes internos al sector y en la asignación de recursos en el conjunto de la economía (Antolín, 1997)

En este trabajo me propongo analizar las etapas de introdución de esta nueva forma de energía y de consolidación del sector eléctrico español en el período 1875-1950, caracterizado por la gestión privada, escasamente regulada, de los recursos ${ }^{9}$. En las páginas que siguen me fijo en los objetivos, las medidas adoptadas y los resultados obtenidos por la iniciativa privada y la política pública en la gestión de los recursos eléctricos. El objetivo último es evaluar sus consecuencias en diversas dimensiones: en términos de eficiencia, atendiendo a costes y asignación de recursos, en la redistribución de riqueza y en el crecimiento económico. En el período considerado, el sector privado tomó la iniciativa en la introducción y puso los medios para el desarrollo del sector en sus primeros setenta y cinco años de actividad. El Estado también participó en su desarrollo desde los inicios, aunque tímidamente. Su objetivo fue abrir los cauces para facilitar la producción y suministro de este nuevo producto cuando la iniciativa privada incidía en el ámbito de competencias públicas. La electricidad se abastece durante este período a través de monopolios locales, con un amplio control de sus mercados, gracias al cual consiguen y mantienen acuerdos sobre la capacidad productiva del sector, las características del servicio

${ }^{9}$ El año 1950 , en el que concluyo el estudio, es el anterior al período de fuerte intervención del Estado en este sector. Ésta se inició con la publicación el 12 de enero de 1951, para entrar en vigor el 1 de enero de 1953, del Decreto sobre Ordenación de la Distribución de la Energía, que implicó el establecimiento de un nuevo sistema de tarifación, las tarifas tope unificadas y el establecimiento de un nuevo sistema de remuneración con la creación de OFILE, el organismo responsable de ajustar la retribución a las compañías eléctricas, más allá de lo que percibían en concepto de ingresos por venta de energia. Las medidas adoptadas en los años cuarenta no alteraron las reglas de juego vigentes en el período anterior. La que puede parecer más intervencionista, consistente en la congelación explícita de tarifas, no hacía más que reiterar una de las condiciones incluidas en los contratos de concesión de suministro otorgados a las compañías. Ésta consistía en que no podían aumentarse los precios más allá de los negociados con la autoridad competente. 
y los precios de venta, así como relaciones fluidas con la administración pública. La sección 2 se centra en el origen y desarrollo de la industria de suministro eléctrico por iniciativa del capital privado, durante el período formativo. En la sección 3 se describe la estrategia de desarrollo seguida por las grandes hidroeléctricas en el período de consolidación de los monopolios locales. En la sección 4 se estudian los distintos pasos por los que se fue conformando el marco institucional, acorde con las características del modelo de relaciones entre industria y administración. La sección 5 analiza las políticas de producción y precios de las eléctricas, y algunas de sus consecuencias. En la sección 6 se agrupan las principales conclusiones ya alcanzadas en las anteriores, implícita o explícitamente, sobre las consecuencias de las opciones tomadas respecto al desarrollo del sector, y se ofrece una evaluación mas global de los resultados del proceso de electrificación.

\section{LA INTRODUCCIÓN DE LA ELECTRICIDAD, 1875-1900}

Durante el siglo XIx, la baja calidad y los elevados costes de obtención del carbón español dificultaron la incorporación de innovaciones, desarrolladas en Gran Bretaña, que utilizaban energía inanimada ${ }^{10}$. El advenimiento de la electricidad abrió nuevas opciones energéticas y representó la posibilidad de ponerse al día en la modernización de los sectores industriales españoles.

Frente a la pobreza en recursos carboníferos, España disponía, cuando se introdujo la electricidad, de un gran potencial para la generación hidroeléctrica ${ }^{11}$. El aprovechamiento de los recursos se vio facilitado por la Ley de Aguas de 1879 , que establecía el procedimiento para el aprovechamiento de los saltos de agua en cauces públicos. Ante estas posibilidades,

${ }^{10}$ La obra de Coll y Sudrià (1987) contiene un estudio exhaustivo sobre el carbón español. Para un análisis de las limitaciones impuestas por el carbón español al desarrollo de los sectores industriales vinculados a la primera revolución industrial, ver Nadal (1983). El trabajo de Sudrià (1997) contiene la revisión más completa y reciente del papel de los recursos energéticos españoles en el crecimiento económico.

"En la memoria del consejo de administración de Hidroeléctrica Ibérica de 1902 se transcriben los resultados de un estudio en el que se compara el coste en infraestructura del salto de 16.000 caballos, en el Ródano, que abastece Lyon con los de aquella sociedad, para concluir sobre la ventaja comparativa de nuestros recursos hidráulicos: «lo accidentado del suelo de la Península, tan desfavorable bajo el punto de vista indicado (la actividad comercial), hace que sea un país privilegiado para el aprovechamiento de saitos de agua». 
la producción de electricidad se inició sin desfases cronológicos respecto a los países industriales avanzados ${ }^{12}$. La electricidad despertaba entusiasmos; se conocían las innovaciones más importantes y se incorporaban rápidamente. La primera instalación de producción para el suministro de electricidad para alumbrado a establecimientos comerciales se construyó en Barcelona, en 1873, a iniciativa del ingeniero N. Xifrá y con capital de T. Dalmau, un fabricante de instrumentos ópticos. Dicha instalación utilizaba máquinas Gramme, cuyo primer prototipo eficiente es de 1870 y patente del año 1874. La primera gran empresa eléctrica, fundada en Barcelona en 1881, fue la Sociedad Española de Electricidad ${ }^{13}$. En el momento de su constitución estaba dotada de un capital social de tres millones de pesetas. Su objeto era la producción de material eléctrico y electricidad. Según el periódico L'Electricien de París, dicha sociedad era la número seis de las constituidas para tal propósito en el mundo (García de la Infanta, 1986). Fue también pionera la electrificación para alumbrado público de la ciudad de Gerona. En dicha ciudad se inauguró un circuito de corriente alterna en 1886, sistema éste de transmisión con patente del año 1882. La Exposición Internacional de París, en el verano de 1881, fue el primer certamen en que se muestran los últimos avances de la tecnología eléctrica. En ella participaron de forma destacada los especialistas españoles del ramo ${ }^{14}$.

Siguiendo el ejemplo de N. Xifra y T. Dalmau, la introducción de la electricidad en España en las últimas décadas del siglo xIX se hizo por iniciativa de empresas instaladoras con concesiones para la producción y/o la importación de equipo eléctrico extranjero. Al principio, dadas las posibilidades de la tecnología, cada instalación tenía una capacidad de producción muy limitada y consiguientemente, unos costes de infraestructura reducidos. Esto explica que, a la vez que las primeras empresas comerciales, también proliferaran instalaciones autoproductoras que abastecían los con-

${ }^{12}$ En el texto de la Estadística de la Industria Eléctrica en España de fines de 1901 del Ministerio de Fomento, se observa que el número de intalaciones eléctricas en la Península había ido aumentando notablemente de año en año, y de un modo casi constante, con un incremento anual medio de 7.317 kilovatios en los nueve años documentados (1893-1901). Dicho progreso le lleva a conluir que kel suministro y distribución de luz, la tracción eléctrica y más modernamente el transporte y distribución de fuerza, alcanzan un desarrollo comparable, y aún superior, al obtenido en las naciones más adelantadas».

${ }_{13}$ Maluquer de Motes (1992) analiza exhaustivamente las viscisitudes del proyecto definido por la Sociedad Española de Electricidad.

${ }^{14}$ Esta exposición, visitada por 600.000 personas, había contado con 1.004 expositores, 19 de ellos españoles, y en ella se adjudicaron 614 premios, ocho de los cuales fueron para españoles (García de la Infanta, 1986). 
sumos de electricidad para fuerza motriz, tracción y/o alumbrado de numerosos establecimientos industriales y comerciales. En las grandes poblaciones se crearon las primeras empresas de producción y suministro a terceros, que inicialmente cubrían un radio muy pequeño. En su financiación participaron los compañias de suministro de gas ya establecidas, que ampliaban su negocio al suministro de electricidad para evitar posibles competencias. Otra aportación importante de capital e iniciativa empresarial, en los orígenes de las empresas de suministro, partió de las compañías extranjeras de equipo eléctrico o de los grupos financieros que las respaldaban. El objetivo de dichas inversiones era asegurarse y ampliar el mercado para sus productos ${ }^{15}$. No es de extrañar, por tanto, que las contribuciones de capital extranjero dejaran de aumentar o, incluso en algunos casos, que se vendieran a accionistas nacionales, una vez que las compañías recién creadas estaban en condiciones de suministrar electricidad. En la estadística sobre instalaciones eléctricas de 1901, en España aparecen registradas 859 centrales productoras, 648 de servicio público y 211 de uso particular, sumando una potencia total de unos $94.164 \mathrm{kw}$, de los que el 61 por 100 era de origen térmico y el resto hidráulico.

Iniciado sin desfases cronológicos respecto a los países industriales avanzados, en 1900 el consumo per cápita español (10,2 kwh) se sitúa entre las primeras posiciones, por debajo del de $\operatorname{EEUU~}(64,9 \mathrm{kwh})$ y Alemania (31,8 kwh), pero por encima del de Francia (7,59 kwh), el Reino Unido $(5,2 \mathrm{kwh})$ e Italia (3,3 kwh) (véase tabla 3 más adelante). Su importancia relativa en el período de introducción de esta forma de energía se puede explicar por el atraso relativo en la difusión de la máquina a vapor y el gas de alumbrado que tuvieron que abastecerse de carbón caro, a las expectativas favorables suscitadas por la electricidad, y a la abundancia de iniciativas empresariales surgidas en este período.

Desde el principio se utilizó la electricidad como fuerza motriz, en aplicaciones industriales para las que la máquina a vapor resultaba demasiado aparatosa y en la tracción, en este caso por parte de compañias de tranvías que producian electricidad para su propio consumo. No obstante, el uso más difundido fue el alumbrado. En la década de 1880 se llevó a cabo el alumbrado público por arco voltaico de las ciudades más importantes. En la década siguiente, cuando se perfeccionó el sistema de alumbrado con lámpara de filamentos de Edison (patente de 1879), al alum-

${ }^{15} \mathrm{La}$ AEG inició sus actividades en España con la creación de la Compañía General Madrileña de Electricidad, en 1890 , y llegó a crear 34 pequeñas centrales para el suministro de diversas poblaciones españolas. La participación de Siemens y Schukert fue menor. 
brado público le siguió el privado. Como consecuencia de estos desarrollos, y dada la escasa implantación de la luz de gas, España fue el país europeo que tuvo, en las primeras décadas del siglo, una mayor proporción de viviendas urbanas abastecidas de electricidad. No obstante, dados los precios a los que se comercializaba ésta y el nivel de renta de los consumidores urbanos, el consumo per cápita en concepto de alumbrado y otros usos domésticos siempre se mantuvo muy bajo ${ }^{16}$.

\section{LA CONSOLIDACIÓN DE MONOPOLIOS LOCALES}

El progreso, durante los últimos años del siglo, en los equipos de producción y transporte, desde la introducción de la corriente alterna (1882) y el transformador trifásico (1891), permitió la explotación masiva de los recursos hidráulicos. Dada la ventaja comparativa de que gozaba el país en este tipo de recursos, dichas innovaciones representaron un fuerte estímulo al desarrollo de la industria eléctrica española ${ }^{17}$. En un período de rápido cambio tecnológico, donde cada nuevo proyecto representaba un nuevo récord histórico, los saltos y las líneas de transporte a larga distancia españoles estuvieron entre los pioneros ${ }^{18}$.

Una vez disponible la tecnología para la generación hidráulica, y dadas las ventajas que confiere la titularidad de concesiones de aprovechamiento

${ }^{16}$ Para la mayoría de los consumidores y hasta épocas muy avanzadas, la sustitución de la vela por la bombilla no significó una mejora sustancial en la calidad de la iluminación, ni el acceso a la amplia gama de servicios que la electrificación de los hogares hizo posibles, a partir de la segunda década del siglo, en otros países. Según Arrúe (1935) durante la década de los años 1930, los hogares españoles seguían utilizando bombillas de 10 vatios, y el consumo per cápita de electricidad para alumbrado era de $22 \mathrm{kwh}$ al año. Éste era el más bajo de Europa después del de la URSS. Comparativamente, el consumo per cápita de Francia y de Estados Unidos era dos o tres veces superior al español respectivamente.

${ }^{17}$ La ventaja relativa de los recursos hidráulicos respecto al carbón se demuestra en la preferencia de los productores por la generación hidroeléctrica. En el periodo anterior a 1900, de predominancia de pequeños autoproductores con consumos situados en zonas urbanas, el porcentaje de electricidad de origen hidráulico, como vimos en páginas anteriores, fue del 39 por 100. En 1929, primer año para el que disponemos de estadísticas fiables, la electricidad de origen térmico representaba sólo un 10 por 100 de la producción total. En fechas más recientes, y en un contexto internacional en que los combustibles líquidos de importación están igualmente disponibles para todos, España es uno de los países europeos con mayor proporción de generación hidroeléctrica. Según los OECD Energy Balances, en el año 1982-1983, la hidroelectricidad representaba un 11,8 por 100 del consumo interior de energia primaria, mientas que en EEUU dicha proporción era sólo el 3,6 por 100 y un 7 por 100 en Italia, país con una dotación de recursos energéticos similar.

${ }_{18}$ De acuerdo con sus promotores, la linea de transporte a larga distancia de corriente alterna para abastecer Zaragoza en 1901 fue el segundo proyecto de esta naturaleza en Europa. 
de los recursos hidráulicos a los primeros en llegar y las economías de escala propias del suministro de electricidad, la constitución de monopolios locales tan solo requirió la presencia de capital e iniciativa empresarial. A excepción del mercado catalán, la mayor parte de los grandes proyectos hidroeléctricos fueron financiados con capital español, promocionados por bancos y realizados por empresarios españoles, con liderazgo claro del capital y empresariado vasco. La escasa presencia de iniciativa empresarial y capital extranjero a partir de 1900 se puede explicar, en gran parte, por las dificultades que se fueron apareciendo a su ejercicio en España ${ }^{19}$. En los primeros años del siglo se crearon, con el respaldo del Banco de Vizcaya y el Banco de Bilbao, las primeras grandes empresas del sector. Hidroeléctrica Ibérica (1901), con abundante capacidad de generación (89.970 CV), se propuso abastecer el País Vasco, Santander, el País Valenciano, Madrid y zonas industriales catalanas. Una vez concluido el primer proyecto, el aprovechamiento de los saltos de Quintana y Leizarán (1904) para el abastecimiento del País Vasco, el consejo de administración de Hidroeléctrica Ibérica decidió limitarse a la gestión del mercado vasco y crear filiales, en las que se reservó el control mayoritario y las tareas de dirección, para el suministro del resto de mercados previstos en el proyecto inicial. Así, para el abastecimiento de Santander se creó la Electra de Viesgo (1906), el abastecimiento de Valencia y Madrid se realizó a través de Hidroeléctrica Española (1907), mientras que se preveía abastecer Sabadell y Tarrasa a través de Hidroeléctrica del Segre. La segunda gran empresa vasca fue Saltos del Duero. El origen del proyecto, la explotación de los

A su vez, el transporte de 60.000 voltios a $250 \mathrm{~km}$., por la Hidroeléctrica Española, para el abastecimiento de Madrid fue el mayor de Europa en el momento de su puesta en marcha.

${ }^{19}$ Así, por Decreto de 7 de diciembre de 1900 se impedía que los extranjeros se presentaran a la adjudicación de servicios públicos, y por el de 14 de febrero de 1907 se obligaba a utilizar artículos nacionales en el suministro de dichos servicios. A las dificultades de tipo legal hay que añadir el incremento de las cargas impositivas por las que aquéllos se vieron afectados. Como consecuencia de diversas disposiciones de 1900 se fueron reduciendo los beneficios percibidos por las compañias extranjeras. Éstas debían pagar impuestos sobre el capital social, sobre dividendos y sobre los intereses de las obligaciones. Además, las decisiones tomadas por el Jurado de Utilidades a este respecto eran inapelables. Concluida la Primera Guerra Mundial, la presión se hizo más fuerte. Las compañías extranjeras que, creadas antes del cambio de siglo, seguían operando en España, perdieron la facultad de renovar los contratos de suministro, mientras se aumentaban nuevamente los impuestos. Aprovechando los beneficios extraordinarios obtenidos por los españoles durante la guerra, a los pocos años de su conclusión gran número de sociedades extranjeras fueron adquiridas por grupos financieros españoles (Antolín, 1991). 
saltos próximos a la frontera con Portugal, se remonta a $1905^{20}$. Junto a las empresas vascas, en los primeros años del siglo surgieron ya las otras grandes empresas que constituirían el oligopolio eléctrico español (tabla 1) ${ }^{21}$.

En España la creación de monopolios locales fue posible porque se dispunso de medios para crear grandes empresas de suministro: información puntual sobre las claves de una industria intensiva en tecnología y en constante evolución, fácil acceso a dotaciones de energía primaria, abundantes recursos de capital e iniciativa empresarial. El caso más claro y eficaz de configuración de un monopolio fue el establecimiento de Hidroeléctrica Ibérica en el mercado vasco ${ }^{22}$. El hecho diferencial en este caso fue que esta empresa supo anticiparse a la competencia. Se constituyó en 1901, en un momento en que se vislumbraba la posibilidad de aprovechar comercialmente la hidroelectricidad. Su conexión con el Banco de Vizcaya le permitió disponer de recursos financieros a la vez abundantes y flexibles. Planificó su ámbito de actividad de manera que le fuera posible capturar las economías de escala propias del negocio eléctrico, estableciéndose en los mercados con mayor capacidad de consumo y con demanda más diversificada. Para ello, antes de constituirla, sus promotores habían obtenido concesiones de saltos por un potencial superior al que era previsible explotar a corto plazo. Con ello controló los recursos de energía primaria susceptibles de abastecer los mercados a los que se orientaba, disuadiendo la entrada de posibles competidores. En Andalucía y otras zonas de la Península, contaron con empresas de tamaño suficiente y constituidas en circunstancias similares a las de HEI, por lo que podemos suponer procesos parecidos al de ésta ${ }^{23}$.

${ }^{20}$ En dicho año se creó la Sociedad General de Transportes Eléctricos por iniciativa de José Orbegozo, que dirigiría la empresa hasta su muerte, acaecida en 1939, y con el apoyo económico de José Luis de Villabaso, director del Banco de Bilbao, y Horacio Echevarrieta, empresario y financiero. Este proyecto una vez realizado (1935), le permitió disponer de una capacidad de $280.000 \mathrm{kw}$, superior a la de cualquier otra empresa europea. $\mathrm{Su}$ retraso se debió al insuficiente desarrollo de las normas internacionales sobre aprovechamiento de recursos hidráulicos compartidos por dos países (Machimbarrena, 1941).

${ }^{21}$ Hidroeléctrica del Cantábrico y FENOSA se crearon en momentos de fuerte crecimiento de la demanda, con la participación mayoritaria de la gran empresa establecida en el mercado en cuestión.

${ }^{22}$ Las observaciones sobre la estrategia empresarial de esta sociedad se basan en los resultados de un trabajo anterior, Antolín (1996).

${ }^{23}$ Véase los estudios de Germán (ed.) (1990), Garrués (1993 y 1998), Núñez (1993), la monografia de la Fundación Sevillana de Electricidad (1994) y Cayón (1997) sobre el desarrollo del sector eléctrico en varias áreas de mercado. 
En el otro extremo, la consolidación de monopolios para el abastecimiento de Madríd y Cataluña fue algo más tardía y laboriosa. La competencia para lograr el abastecimiento de Madrid en condiciones de monopolio se establece entre dos contendientes: Unión Eléctrica Madrileña, dirigida por el grupo empresarial que había disfrutado del monopolio del gas, y que suministraba la mayor parte del mercado madrileño cuando Hidroeléctrica Española, con una capacidad de producción mayor, se propuso el abastecimiento de Madrid. A los tres años de tanteos por el control, vía reducciones de precios, en 1913 acuerdan el reparto del mercado a partes iguales (García de la Infanta, 1986) ${ }^{24}$. Desde las últimas décadas del siglo $\mathrm{xx}$, el mercado catalán fue surtido por numerosas térmicas e hidroeléctricas de tamaño pequeño y medio. Hasta 1911, con la constitución de tres grandes empresas, no surge la posibilidad de consolidación de grandes suministradoras. En este caso una de las tres grandes, la Barcelona Traction Light and Power, dispuso de suficiente capacidad para forzar la absorción de empresas rivales y adoptar a los pocos años el control mayoritario del mercado catalán ${ }^{25}$.

La tabla 1 relaciona las empresas que al final del período estudiado constituían el oligopolio eléctrico español. La mayoría de ellas se crearon en la primera década del siglo o en los primeros años de la segunda. Aquellas que muestran una fecha más tardía se originaron a través de procesos de unión o fusión. En este caso destaco a la compañía que dirigió dicho proceso y su fecha de creación. Con el tiempo, fueron consolidando sus áreas de mercado iniciales y ampliándolas mediante fusiones, control mayoritario del capital de otras empresas, o control piramidal ${ }^{26}$. En 1930, segundo año consecutivo para el que, por primera vez, tenemos información detallada y centralizada sobre la capacidad y actividades de producción

${ }^{24}$ Para un estudio detallado del proceso de competencia en la extensión del suministro eléctrico de Madrid, ver Aubanell (1992).

${ }^{25} \mathrm{La}$ Traction fue financiada con carácter casi exclusivo por capital extranjero. Los grandes suscriptores fueron: el Canadian Bank of Commerce de Toronto, el London Bank of Scotland de Londres, la Société Générale de París, Syollearts et Lorrenstein de Bruselas y Dan Fishey and Co. de Londres. Para un estudio minucioso del desarrollo de la oferta de electricidad de que disfrutó el mercado catalán, ver Maluquer de Motes (1983).

26 Por lo que conozco de la experiencia de Hidroeléctrica lbérica, en un primer periodo, la empresa con poder de monopolio se limita a abastecer el área de mercado que dispone de una intensidad y diversidad horaria de demanda que le permite la mejor remuneración a sus actividades mientras subsisten pequeños suministradores y autoproductores abasteciendo las demandas marginales. La cobertura de estas últimas se hace efectiva por parte del monopolista cuando se hace más intensiva - como ocurrió en los años veinte-, cuando el desarrollo de la tecnología lo recomendaba, cuando existian amenazas creíbles de competencia - como ocurrió en los años treinta con la puesta en explotación de los 


\section{TABLA 1}

Empresas del oligopolio español de electricidad (1949)

(Capital superior a los 100 millones de pesetas)

\begin{tabular}{|c|c|c|c|c|c|}
\hline Empresas & $\begin{array}{l}\text { Capital } \\
\text { (mill.) }\end{array}$ & $\begin{array}{l}\text { Potencia } \\
\quad(k w)\end{array}$ & $\begin{array}{l}\text { Producción } \\
\text { (kwh) }\end{array}$ & $\begin{array}{l}\text { Numero } \\
\text { empresas } \\
\text { sistema } \\
\text { piramidal }\end{array}$ & $\begin{array}{l}\text { Número } \\
\text { provincias }\end{array}$ \\
\hline \multicolumn{6}{|l|}{ Hidroeléctrica Ibérica «Iberduero», } \\
\hline $\begin{array}{l}\text { Unión Eléctrica Madrileña, } 1912 \\
\text { (Cía. General Madrileña de Elec- } \\
\text { tricidad, 1890)......................... }\end{array}$ & 465 & 45 & 94 & 9 & 4 \\
\hline Hidroeléctrica Española, 1907 ........ & 391 & 194 & 648 & 10 & 3 \\
\hline $\begin{array}{l}\text { Eléctricas Reunidas de Zaragoza, } \\
1910 \text { (Teledinámica del Gállego, } \\
\text { 1901) }\end{array}$ & 300 & 28 & 95 & 6 & - \\
\hline Cía. Sevillana de Electricidad, 1894 & 300 & 74 & 294 & 4 & 4 \\
\hline 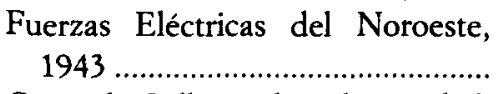 & 250 & 17 & 42 & & \\
\hline $\begin{array}{r}\text { General Gallega de Electricidad, } \\
1899 \ldots \ldots \ldots \ldots \ldots \ldots \ldots \ldots \ldots \ldots \ldots \ldots \ldots \ldots \ldots \ldots \ldots \ldots \ldots \ldots \ldots \ldots\end{array}$ & 250 & 44 & 128 & 3 & 4 \\
\hline Electra del Viesgo, $1906 \ldots \ldots \ldots \ldots \ldots \ldots$ & 240 & 105 & 336 & 10 & 2 \\
\hline Cía. Anónima Mengemor, 1904 ...... & 200 & 66 & 147 & 10 & 2 \\
\hline $\begin{array}{l}\text { Hidroeléctrica del Chorro, } 1903 \ldots . . \\
\text { Riegos y Fuerzas del Ebro, } 1913\end{array}$ & 150 & 42 & 92 & 13 & 2 \\
\hline $\begin{array}{l}\text { (Barcelona Traction, 1911) .......... } \\
\text { Cía. de Fluido Eléctrico, } 1920 \text { (Ca- }\end{array}$ & 150 & 194 & 254 & 8 & 4 \\
\hline $\begin{array}{c}\text { talana de Gas y Electricidad, } \\
1901) \ldots \ldots \ldots \ldots \ldots \ldots \ldots \ldots \ldots \ldots \ldots \ldots \ldots \ldots \ldots \ldots \ldots \ldots \ldots \ldots \ldots \ldots \ldots \ldots\end{array}$ & 120 & 39 & 181 & - & \\
\hline 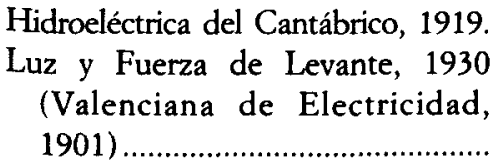 & 120 & 24 & 119 & - & 1 \\
\hline
\end{tabular}

FuentE: Elaborado con información contenida en Muñoz Linares (1933), Caps. II, III y IV.

recursos de Saltos del Duero-, o cuando se dan amenazas de intervención pública, como ocurrió ante los fallos de oferta en los años cuarenta. 
del conjunto de empresas del sector, se estima que las diez mayores, pertenecientes a los conglomerados vasco y catalán, contribuían con un 72 por 100 de la capacidad y el 68 por 100 de la producción total.

En un estudio sobre el poder de monopolio de las empresas eléctricas españolas, Muñoz Linares (1954) describe la importancia relativa de los grupos empresariales españoles y las áreas de mercado que abastacen. Según este autor, en los años cuarenta, el sector eléctrico estaba presidido por un oligopolio compuesto por las catorce empresas que aparecen en la tabla 1. A éstas les correspondía una inversión en capital equivalente al 59 por 100 , o al 66 por 100 si consideramos el conjunto de las 111 empresas del sistema piramidal del que eran vértices, respecto al total invertido en el sector. Dichos grupos, con una capacidad equivalente al 72 por 100 del total nacional, actuaban como monopolios locales y abastecían, sin competir entre ellos, el 70 por 100 del consumo español.

La tabla 2 muestra la extensión de los mercados de las empresas del oligopolio. En cada provincia se indica el porcentaje del consumo cubierto por la empresa del oligopolio que Muñoz Linares considera dominante. No se observa competencia entre las empresas del oligopolio, puesto que o el grado de penetración para la venta de energía de cada una de ellas en los mercados de las demás es muy bajo y variable, o comparten el mercado a base de llegar a acuerdos estables ${ }^{27}$. En trece provincias espanolas las empresas del oligopolio no operan literalmente como monopolistas, puesto que no cubren una porción del mercado suficiente como para actuar como líder en precios ${ }^{28}$. No obstante, casi siempre hay una empresa del oligopolio, y nunca más de una, que tiene una participación importante y que eventualmente se hará dominante al cabo de unos años. Así, de éstas, siete estaban bajo la influencia de Iberduero, dos de Hidroeléctrica Española, una de Mengemor, una de Sevillana, y en la provincia de Zaragoza actuaban varias empresas ligadas al sistema piramidal de dos miembros del oligopolio: Eléctricas Reunidas de Zaragoza e Iberduero. Según Muñoz Linares, el cártel eléctrico español funcionó con una gran estabilidad. La cuantía y frecuencia de la penetración entre las empresas

${ }^{27}$ El ejemplo más conocido de esta última situación es el del abastecimiento de Madrid realizado a partes iguales por UEM y HE. Para asegurarse el cumplimiento del acuerdo crearon un Comité Mixto que hacía de intermediario entre las compañías abastecedoras y los consumidores, y era el responsable de la política de comercialización y recaudación de ingresos (Cayón, 1997, pp. 83-89)

${ }^{28}$ Dichas provincias son: Alicante, Cáceres, Ciudad Real, Huelva, León, Logroño, Murcia, Navarra, Palencia, Salamanca, Teruel, Toledo y Zaragoza. 


\section{TABLA 2}

Área de mercado de las empresas del oligopolio (1949)

- Hidroeléctrica Ibérica (Iberduero): Álava (95), Burgos (81), Guipúzcoa (36), Huesca (46), Soria (83), Valladolid (77), Vizcaya (80), Zamora (99).

- Unión Eléctrica Madrileña: Ávila (93), Guadalajara (93), Madrid (44), Segovia (56).

- Hiroeléctrica Española: Albacete (72), Cuenca (61), Valencia (85).

- Sevillana de Electricidad: Badajoz (94), Cádiz (21), Málaga (51), Sevilla (86).

- General Gallega de Electricidad: La Coruña (54), Lugo (54), Orense (75), Pontevedra (98).

- Electra de Viesgo: Santander (39), Oviedo (53).

- Mengemor: Córdoba (53), Jaén (82).

- Hidroeléctrica del Chorro: Almería (66), Granada (72)

- Riegos y Fuerzas del Ebro: Barcelona (69), Gerona (53), Lérida (73), Tarragona (100).

- Luz y Fuerzas de Levante: Castellón (99).

LECTURA: Las cifras éntre paréntesis son los porcentaje de la demanda suministrada en cada provincia.

FUENTE: Elaborado con información contenida en Muñoz Linares (1954), pp. 121-158.

del oligopolio, que se da cuando una empresa A suministra en el mercado de $\mathrm{B}$, es poco importante.

La facilidad con la que aparentemente se mantuvieron los acuerdos del cártel se puede explicar porque en la industria eléctrica es relativamente fácil preservar los mercados de los monopolios locales. Penetrarlos es difícil porque el suministro requiere infraestructura y porque, en general, los contratos de suministro a grandes consumidores o distribuidoras pueden tener reconocimiento legal y se establecen para períodos prolongados. Además, cuando la energía primaria utilizada en la generación es hidroeléctrica, la cantidad de recursos disponibles es limitada y la expansión de la capacidad productiva de cada productor está predeterminada por la asignación previa de los recursos hidráulicos. Otras circunstancias, surgidas en el contexto de la estrategia de las empresas del oligopolio español, explican la ausencia de competencia en el sector. Entre éstas destaca la existencia de afinidades entre grupos de grandes empresas que participan de capitales y servicios bancarios comunes.

En este sentido, Uriarte (1949) diferencia cinco grupos de empresas entre las que se dan afinidades por participación en capital o por sus rela- 
MAPA 1

Mercados abastecidos por las empresas del oligopolio (1949)

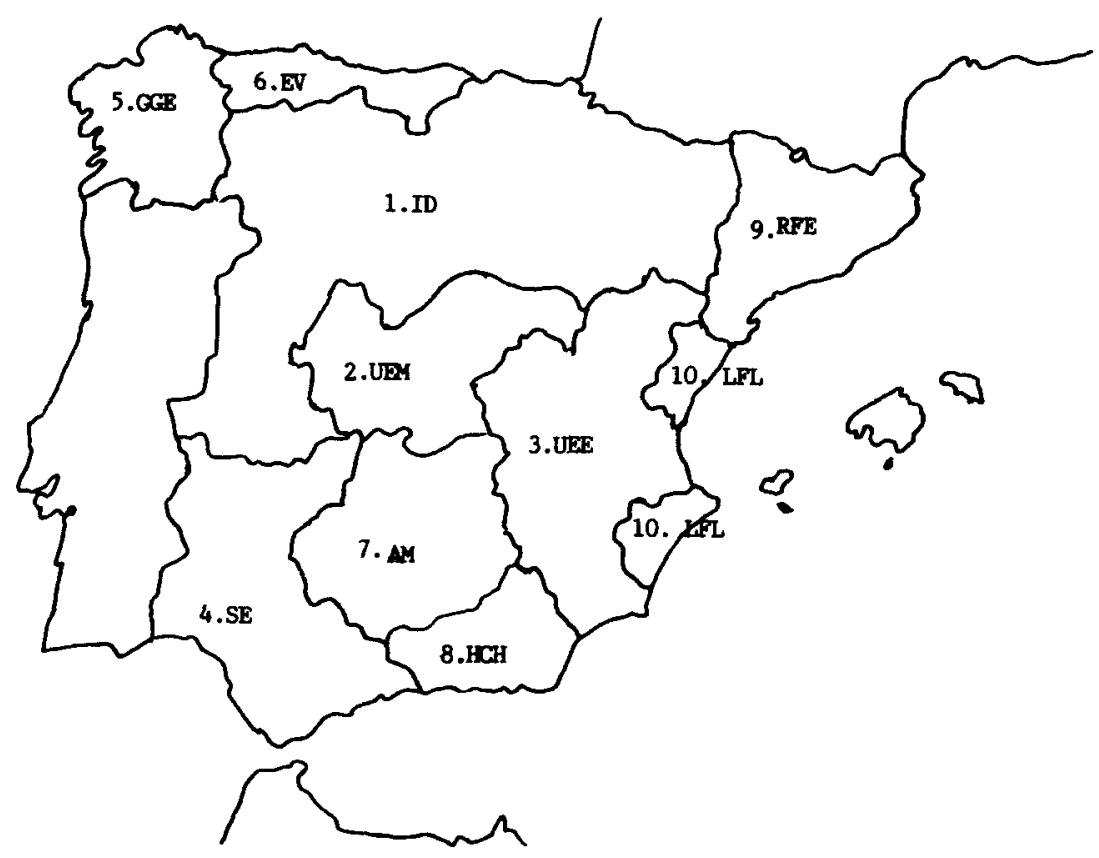

ciones bancarias. Éstas incluyen a las 128 mayores, que disponen del 81 por 100 de la potencia instalada y son responsables del 92 por 100 de la producción nacional (datos de la Cámara Oficial de Productores y Distribuidores de Electricidad) ${ }^{29}$. Otros recursos que dificultaban la competencia no deseada por el colectivo eran el intercambio de acciones entre compañías, y el que las grandes empresas del sector compartieran consejeros comunes (véase el gráfico 1). Su presencia facilitaba acuerdos de colaboración, a la vez que daba transparencia a posibles intentos de conductas de rivalidad, poniendo trabas a su realización. Si tenemos en cuenta su

${ }^{29}$ Estos grupos son: a) Vasco Navarro - 66 empresas (Iberduero, Española, Viesgo, Sevillana, ERZ...) -; b) Canadiense - 12 empresas (Riegos, Productora, E. M. de Sástago, E. E. de Cataluña...) - ; c) Unión -27 empresas (Madrileña, Alberche, Cooperativa del Fluido Eléctrico, E. de Langreo, Riegos de Levante...)-, d) Gallegas y Chorro - 11 empresas-, y e) Eléctricas importantes que mantienen contactos lejanos con otras -12 empresas (Mengemor, H. del Cantábrico, Lute, Irati...). 


\section{GRÁFICO 1}

Consejeros comunes en las empresas del ologopolio

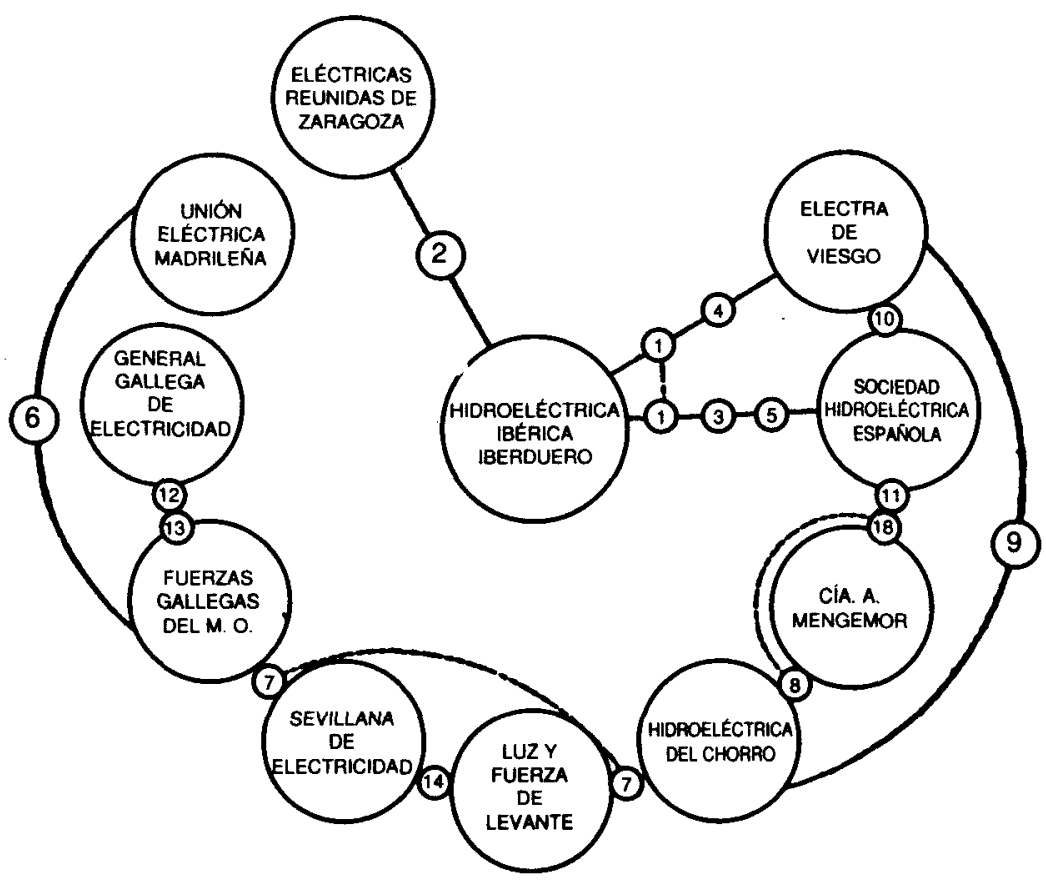

estrecha conexión con grupos bancarios, y la forma de organización de que se dotaron (consejeros comunes, intercambio de acciones) podemos concluir que las catorce grandes compañías descritas por Muñoz Linares actuaron como oligopolio, con un sistema de acuerdos estables, que supervisaba la actuación de monopolios locales de producción y suministro y, lo que es más importante, planificaba decisiones sobre inversión, sistema de precios y relaciones con la Administración.

\section{LA CONFIGURACIÓN DEL MARCO INSTTTUCIONAL}

La posibilidad de aprovechar los recursos hidráulicos para la producción de electricidad y la progresiva ampliación de los usos y consumos de esta nueva forma de energía generaron una problemática específica, que requirió 
nuevos marcos organizativos y normas para canalizar iniciativas y consolidar los proyectos más audaces.

Desde el principio fue sentida la necesidad de un marco institucional específico, y su configuración fue propuesta y negociada por los grandes productores. En los comienzos de la industria, los empresarios denunciaban insuficiencias y avanzaban proyectos, ya fuera directamente en las distintas dependencias gubernamentales o a través de foros que se fueron creando para este propósito. Los empresarios más activos del sector fueron los directores de las empresas del bolding vasco. Entre ellos destaca Juan Urrutia, fundador en 1901 de Hidroeléctrica Ibérica y del resto de empresas respaldadas por el Banco de Vizcaya, y más tarde promotor y director de la Cámara Oficial de Productores y Distribuidores de Electricidad. A un nivel más general, entre sus principales contribuciones cabe destacar el proyecto de modificación de la Ley de Aguas de 1879, que inspiró el decreto Cambó de septiembre de 1918, así como diversas propuestas referentes a la necesaria integración del sector eléctrico español. Otra figura relevante fue José Orbegozo, fundador de Saltos del Duero en 1909, con el respaldo del Banco de Bilbao, quien, además de dirigir la empresa hasta 1935, contribuyó al desarrollo del derecho internacional sobre aprovechamientos hidráulicos y apeló a la corresponsabilidad del estado en la financiación de los grandes proyectos hidroeléctricos.

El nuevo marco organizativo empezó a tomar cuerpo con la creación en 1912 de la Comisión Permanente Española de Electricidad. Su objetivo consistió en hacerse eco de las necesidades de esta industria, dando a conocer las posibilidades de esta nueva forma de energía y facilitando los medios técnicos y legales ${ }^{30}$. El segundo organismo creado, en esta ocasión para defender los intereses de las grandes compañías, fue la Cámara Oficial de Productores y Distribuidores de Electricidad, constituida formalmente en 1920 y reconocida oficialmente en $1929^{31}$. Entre sus deberes figuraban la cooperación con organismos del Estado, facilitando información pertinente para la reestructuración de aprovechamientos eléctricos y la modi-

${ }^{30}$ Dicha comisión estaba formada por académicos, representantes de las compañías de la electricidad establecidas en España y, mayoritariamente, representantes del Gobierno. $\mathrm{Su}$ objetivo fue asesorar y proponer al Gobierno, por iniciativa propia o a instancia de particulares, todo asunto referente a las aplicaciones industriales de la electricidad. Además llevaba la representación española en las reuniones internacionales y se relacionaba con los laboratorios extranjeros.

${ }^{31}$ El motivo de su creación fue dar respuesta a los intentos de intervención de precios de la electricidad por parte de la Administración ante la carestía del carbón durante la Primera Guerra Mundial. 
ficación de reglamentos de las sociedades que la integraban. Entre sus derechos, los de informar y ser informada, y más específicamente, el de solicitar la concesión de redes especiales de enlace, la constitución de cooperativas de consumo y mancomunidades de producción.

En 1920 se inició un período en el que la participación del Estado incorporó iniciativas propias. Varias circunstancias explican una creciente sensibilidad de los poderes públicos hacia la problemática del sector: a) las dificultades en el suministro de energía y la consiguiente subida de los precios, surgidas por la disminución de las importaciones de carbón durante la primera guerra mundial; b) el mayor protagonismo alcanzado por el sector eléctrico, como consecuencia de su espectacular expansión durante los años de bonanza económica que siguieron a la conclusión de aquella guerra, y $c$ ) la puesta en escena, durante la dictadura del General Primo de Rivera (1921-29), de un proyecto de desarrollo económico, a imagen y semejanza del de la Italia de Mussolini, basado en una economía corporativista con fuerte intervención estatal.

Los primeros organismos oficiales que canalizaron la política pública respecto al sector, en este caso promoviendo y financiando nuevos aprovechamientos hidroeléctricos, fueron las Mancomunidades Hidrográficas, creadas en marzo de $1926^{32}$. Resultado de la nueva orientación fue también la creación, en septiembre de 1929, del Consejo de Energía, primer organismo oficial específico, que quedó adscrito, en noviembre de 1932, al Consejo de Obras Hidráulicas. Su objeto fundacional fue la organización y ordenación del sector eléctrico. La iniciativa más importante fue la del conde de Guadalhorce, ministro de Fomento durante la Dictadura, que abrió, en 1926, un concurso de proyectos para enlazar las térmicas con las hidráulicas, acción orientada a la construcción de la Red Eléctrica Nacional ${ }^{33}$. Para avanzar en esta dirección, el Estado asumió responsabilidades en la mejora de las redes de distribución y enlace para el abastecimiento de los servicios considerados de interés nacional. Consecuentemente, en

${ }^{32}$ Dicho organismo, constituido por todos los concesionarios y usuarios de las aguas fluviales de una cuenca, tuvo como objetivo inmediato la canalización de los auxilios del Estado para la creación de riqueza colectiva mediante una fórmula de coordinación de los intereses privados que la solicitaran. Su impacto sobre el sector eléctrico fue menor.

${ }^{33}$ Los primeros pasos en la unificación de la red se habían dado con la Real Orden de 29 de diciembre de 1918. En ella, el Gobierno solicitaba un informe sobre las condiciones en que el Estado podría construir una red nacional. A tal objeto se creó una comisión, en la que figuraban los ingenieros Urrutia, Madariaga, Artigas y Echarte, que aconsejó la combinación de una red radial y periférica, construida a expensas del Estado y sometida a régimen de canon cuando la utilizaran las empresas. Este proyecto no se realizó porque hubo empresas que no lo aceptaron. 
su marco se diseñaron los primeros proyectos públicos, consistentes en aprovechamientos reservados al Estado para el abastecimiento de energía al ferrocarril y empresas electroquímicas.

Por otro lado, la normalización de los nuevos procesos y relaciones económicas se planteó en ocasión de la creación de las primeras empresas dedicadas a la producción y suministro público ${ }^{34}$. La principal preocupación de la Administración local en el período inicial parece haber sido el control de la peligrosidad de las instalaciones y tendidos eléctricos. Un segundo aspecto en el que se centró la normativa local fue el referente al libramiento de concesiones para el abastecimiento de electricidad a terceros. En los contratos que se negociaban entre empresas de suministro y municipios se preveían las características, calidad y precio de los servicios considerados esenciales, y los derechos y obligaciones que mediaban entre suministrador y clientes. En la primera etapa, el detalle de la normativa se inspiraba en la legislación de otros países, especialmente Francia e Italia (Vidal Burdils, 1940) ${ }^{35}$.

Cuando el desarrollo de la tecnología permitió el aprovechamiento masivo de los recursos hidráulicos para el suministro a terceros, fue preciso el diseño de nuevas normas. Las más importantes fueron: a) la Ley de marzo de1900, en la que aplicando el concepto de utilidad pública a las líneas de tendido eléctrico, se dispuso la servidumbre forzosa de paso de éstas por propiedades de terceros: el propósito de dicha disposición era agilizar la realización de los proyectos y la reducción del coste de las redes de transporte; b) la Orden de diciembre de 1907, denominada de «Verificación de Contadores», que recopiló las normas que habían aparecido en los años inmediatemente anteriores por las que se regulaban las relaciones entre empresas eléctricas y abonados: en estos años el aspecto que preocupaba al legislador era, exclusivamente, la regularidad y continuidad del suministro, mientras que la fijación de tarifas y de precios no tenía limitaciones de carácter general; c) el RD de septiembre de 1918, que

${ }^{34}$ La primera norma específica referente a la electricidad es la de marzo de 1890 , que requería autorización administrativa, a nivel local, para las instalaciones de generación y de transporte (Díaz-Caneja, 1985).

${ }^{35}$ De hecho, las primeras disposiciones legales que contemplan la actuación de las empresas de producción y suministro de electricidad para alumbrado y fuerza fueron las Leyes municipales de 20 de agosto de 1870 y 2 de octubre de 1877 . Éstas conferían a los Ayuntamientos competencia exclusiva en materia de alumbrado público y privado, tanto eléctrico como de gas. De acuerdo con dichas normas, cuando las empresas productoras estaban situadas en el recinto urbano requerían de licencia municipal y estaban sometidas a los acuerdos de policía industrial. 
recogía la normativa específica sobre concesión de aguas públicas para la producción de electricidad: con ello se eliminaban los márgenes de arbitrariedad con que se negociaban hasta entonces, y se racionalizaba y agilizaba el proceso de tramitación. Dicho decreto daba prioridad a los grandes proyectos hidroeléctricos frente a los de otros usuarios.

En el período de creciente sensibilidad pública, a partir de 1920, las disposiciones legales más importantes fueron, por orden cronológico: $a$ ) las relativas a la forma de determinación de los precios de la electricidad, en que la Administración se reservaba mayor protagonismo (1920-1933); b) la declaración del suministro de electricidad como servicio público (1924), y c) la concesión de ayudas económicas a las nuevas construcciones (1924-1929). La RO de agosto de 1920 disponía que la fijación de precios de la energía eléctrica de las nuevas empresas concesionarias requiriese la autorización de la Administración Central. A su vez, declaraba ilegales las elevaciones de precios de las distribuidoras establecidas que no contaran con la autorización de la Administración, y que, en opinión de los portavoces de las empresas, hasta entonces se efectuaban más o menos libremente. Pero la capacidad de obligar el cumplimiento de dichas disposiciones a las nuevas empresas concesionarias no se produciria hasta mucho más tarde. Primero fue precisa la aprobación del RD de abril de 1924 por el que se decidió ordenar el sector a nivel centralizado, declarando servicios públi$\cos$ los suministros de energía eléctrica, agua y gas ${ }^{36}$. De hecho, al nivel de la Administración Central, la reserva de la potestad tarifaria respecto a las nuevas empresas concesionarias no se estableció, por ampliación de los reglamentos que regulaban las relaciones entre suministrador y abonados, hasta los Decretos de marzo de 1931 y diciembre de 1933.

Paralelamente a la responsabilización del Estado en la ordenación del sector, fueron apareciendo disposiciones que establecían exenciones tributarias y canalizaban la ayuda económica pública a la electrificación del país, con contribuciones a proyectos privados y proyectos públicos ${ }^{37}$. En este sentido, las primeras contribuciones sustanciales se hicieron durante la dictadura de Primo de Rivera, en el contexto de una política presu-

${ }^{36}$ A partir de aquella fecha, le correspondió al entonces llamado Ministerio de Transporte, Comercio e Industria la reglamentación de tales servicios para la garantía de la seguridad e interés públicos. De acuerdo con dicho decreto, se requiere la concesión o autorización de la Administración Central para la producción y distribución de energía eléctrica, dejándose a las provincias y municipios las demás intervenciones que pudieran corresponder sobre los detalles de las concesiones y contratos administrativos.

37 Por RD de abril de 1924, exención de impuestos en la constitución y cinco primeros años de funcionamiento de nuevas sociedades. 
puestaria fuertemente orientada a la promoción de obras públicas e inversiones básicas. En el marco de las Mancomunidades Hidrográficas se dieron nuevas concesiones de obras hidráulicas y se ampliaron otras existentes, en las que el Estado cubría la financiación del salto y la amortización de la mitad del coste ${ }^{38}$. Estas ayudas se suspendieron en 1931, durante la Segunda República. La crisis económica de los años treinta y la sobrecapacidad experimentada por el sector productor en aquellos años fueron las razones avanzadas por la Administración para justificar la interrupción de las ayudas del Estado. Por lo que hemos visto, en vísperas de la Guerra Civil, la nueva orientación hacia una mayor intervención de la política pública en la ordenación, regulación y promoción del sector había experimentado un período de definición y, sobre todo, de aplicación sumamente corto. De ello se puede concluir que su impacto fue, en la práctica, muy escaso.

Del conjunto de normas que se fueron perfilando, de la intersección de la iniciativa e intereses privados y públicos en la primera etapa de gestión de los recursos eléctricos, se pueden extraer algunas reflexiones. La mayor parte de las normas se orientaron a materializar los proyectos surgidos de la iniciativa privada. En este sentido, se fueron precisando los procedimientos para acceder al aprovechamiento de los recursos hidráulicos y mejorarlo, se eliminaron los impedimentos en el transporte de electricidad y se facilitó el acceso a los consumidores otorgando concesiones de suministro. Al final del período, aunque con un impacto menor, se dieron estímulos en forma de ayudas y exenciones a la expansión y racionalización del sector.

Mucho más modesta fue la contribución de la normativa en defensa del interés publico, orientada a reconducir los sesgos introducidos por el monopolio privado en el abastecimiento eléctrico. Para empezar, la Administración Pública no explicitó su capacidad y autoridad en materia de abastecimiento eléctrico hasta muy tarde. Así, el abastecimiento eléctrico sólo se declaró servicio público en 1924, y hasta bien entrada la década de 1930 no fueron declaradas de cumplimiento obligatorio las normas surgidas de la Administración.

En cuanto a la contribución a la eficiente gestión de los recursos, cabe señalar los esfuerzos que representan los proyectos de construcción de

${ }^{38}$ En la «Sociedad para la Canalización y Fuerzas del Guadalquivir», 1925; la «Sociedad Hispano-Portuguesa de Transportes Eléctricos», la «Electro Metalúrgica Ibérica», propiedad de Saltos de Alberche, y la «Unión Española de Explosivos», el Estado aportaba el 50 por 100 de su coste y anticipaba el 40 por 100 de la cantidad restante, a reintegrar con un bajo interés en veinte o veinticinco años. 
una red eléctrica nacional, de regulación de los caudales con la construcción de presas en la cabecera de los ríos, de armonización de intereses de los usuarios de recursos hidráulicos a través de la estructuración de confederaciones hidrográficas. En la defensa de los intereses de los consumidores frente al monopolio, destacamos: a) los intentos de controlar arbitrariedades en la fijación de tarifas y en la subida de precios del abastecimiento de las nuevas empresas establecidas en el sector, $\mathrm{y} b$ ) los incentivos económicos para extender el servicio eléctrico hacia áreas descuidadas por la iniciativa privada.

\section{ESTRATEGIA EMPRESARIAL Y REALIZACIONES EN EL MARCO DE LA GESTIÓN PRIVADA}

Dada la estructura de mercado y el marco institucional en el que actuaron las grandes eléctricas, descrito en los apartados anteriores, su estrategia de producción y de precios fue la propia de empresas con monopolios locales, escasamente reguladas y con mercados fuertemente protegidos. Para ejemplificar dicha conducta, en las páginas que siguen, me refiero a la experiencia de una de ellas, Hidroeléctrica Ibérica, empresa emblematica del holding vasco y que he estudiado en detalle en Antolín (1996). El comportamiento de dicha empresa fue coherente con el entorno de mercado en el que actuaron tanto ella como las otras grandes hidroeléctricas, y resulta significativo dado el importante peso relativo de aquel bolding dentro del sector ${ }^{39}$.

Respecto a la estrategia de producción observamos que la electricidad se obtenía preferentemente de la energía hidráulica. Los recursos más codiciados eran los que permitían la generación con economías de escala y al menor coste en infraestructura. Dichas circunstancias se daban en el aprovechamiento de saltos de agua próximos al emplazamiento de los consumos y que gozaran de un caudal, en estiaje, relativamente abundante ${ }^{40}$.

${ }^{39}$ En los primeros años de la posguerra, el valor en acciones y obligaciones de sociedades eléctricas de uno de los bancos del bolding, el Banco de Vizcaya, era de 2.000 millones de pesetas, aproximadamente el 50 por 100 de su cartera de valores industriales. En este período, cuatro de las mayores sociedades participadas por este banco (Iberduero, Hidroeléctrica Española, Sevillana de Electricidad y Electra de Viesgo) cubrían con sus redes el 66 por 100 de la superficie peninsular y abastecian el 46 por 100 de la electricidad consumida en España (Memorias del Banco de Vizcaya, 1956 y 1963).

${ }^{40}$ Los recursos de que disponía HEI en el momento de su constitución, y que le permitieron abastecer la demanda durante sus primeros veinte años de actividad, eran saltos 
El recurso a la producción térmica, necesaria para contrarrestar las irregularidades de la oferta hidráulica, se mantuvo siempre muy bajo. En vísperas de la Guerra Civil, representaba escasamente un 10 por 100 de la producción total ${ }^{41}$. Una de las cuestiones importantes a resolver por los productores de electricidad, en especial por los que utilizan energía hidráulica, tiene que ver con que la puesta en aprovechamiento de los saltos, la canalización y/o la construcción de la presa, el equipo de generación y las líneas de transporte y distribución, requieren la realización de inversiones cuantiosas en planta y equipo de larga duración. Otra cuestión a tener en cuenta, dadas las restricciones que impone el sistema de generación hidroeléctrico, es que cada nuevo salto puesto en explotación implica un aumento súbito de potencia, en general considerable, por lo que la capacidad de producción de las empresas de suministro evoluciona de forma discontinua. Por todo ello, y puesto que la demanda de electricidad crece de forma continua, para optimizar las inversiones al programar sus incrementos de capacidad, las empresas de suministro se enfrentan con un dilema: si las inversiones en nueva planta se anticipan en exceso al crecimiento de la demanda, sufrirán períodos prolongados de sobrecapacidad y el coste del kw abastecido resultará innecesariamente elevado; si, por el contrario, las decisiones de inversión se retrasan demasiado, una porción importante de la demanda puede quedar desatendida.

El rasgo más significativo de la estrategia de inversión de las grandes eléctricas españoles del período fue que, una vez establecidas como monopolio local en su área de influencia, tendieran a mantener la oferta por debajo de la demanda potencial ${ }^{42}$. Así, las ampliaciones de capacidad en antiguos saltos, o la construcción de otros nuevos, no se emprendían hasta que la demanda fuera capaz de absorberla o, incluso, en muchos casos, cuando la nueva potencia estuviera efectivamente contratada ${ }^{43}$. El mantenimiento de la oferta por debajo de la demanda potencial les permitía

no regulados de más de 1.000 caballos de potencia instantánea, con un coste medio de infraestructura de 1.000 pesetas por $\mathrm{kw}$.

${ }^{41}$ Las primeras informaciones sistemáticas sobre la producción de energía eléctrica en España son las publicadas por la Cámara Oficial de Productores y Distribuidores de Electricidad desde 1929, reproducidas en el Anuario Estadístico de España.

${ }^{42}$ En la década de 1930, la ralentización de la demanda y, sobre todo, la puesta en explotación en el año 1935 de las importantes instalaciones de Saltos del Duero llevaron a situaciones de exceso de capacidad. Para prever soluciones a la nueva situación, ya en 1930 se había firmado un pacto de auxilio mutuo entre las hidroeléctricas.

${ }^{43}$ La estrategia de inversión descrita no se contradice con que la industria eléctrica experimente economías de escala. Las economías de escala en la producción hidroeléctrica están condicionadas por la capacidad del salto. Por tanto, la estrategia de no inicar la 
escoger entre una variedad de consumidores, diferenciados por: $a$ ) su esquema de demanda, en términos de cantidad y distribución horaria y estacional, y b) sus disposiciones a pagar ${ }^{44}$. Esta capacidad de elección resultaba óptima para las empresas de suministro porque les permitía reducir a mínimos los costes de operación, y maximizar los ingresos por kw vendido. Para ajustar el coste del kw abastecido, evitando capacidad ociosa, debían seleccionar un subconjunto de clientes cuyos esquemas de demanda fueran complementarios, y capaces de absorber conjuntamente la producción total. Se trataba de ajustar el flujo de la demanda contratado de modo que, por agregación de la demanda de distintos tipos de consumidores, coincidiera con la producción resultante del uso del equipo a plena capacidad ${ }^{45}$. Por lo que respecta a la remuneración, se trataba de seleccionar, dentro de cada tramo horario de demanda, a los consumidores dispuestos a pagar los precios más elevados.

$\mathrm{Al}$ igual que con las decisiones de producción, las empresas eléctricas gozaron de amplios márgenes de libertad para establecer su política de precios, puesto que, tambien en este aspecto, como veíamos en la sección anterior, la intervención estatal fue escasa e ineficaz. El sistema de tarifas que aparecía en las concesiones de suministro municipales era propuesto por las propias compañías eléctricas, dentro de las especificaciones establecidas. De hecho, la especificación de tarifas sólo era obligatoria para los servicios considerados esenciales (básicamente, el alumbrado público y el consumo domiciliario), aunque era habitual que también se hicieran públicas otras, con naturaleza de precios máximos, para usos comerciales e industriales, y que aparecieran como tales en el documento de concesión otorgado por el municipio. Pero, por lo que sabemos, los precios cobrados en la práctica a los grandes consumidores se negociaban individualmente por debajo del máximo establecido en las concesiones de suministro.

explotación hasta asegurarse la colocación de la energía producida es consistente. Las economías de escala en la distribución vienen condicionadas por las características de la demanda. La estrategia de discriminación de precios casi perfecta que se describe más adelante muestra que las empresas disponían de los intrumentos adecuados para tomar las decisiones más favorables, en términos de costes y beneficios, a la hora de decidir el sector de mercado que les interesaba abastecer.

${ }^{44}$ Mientras que el esquema de demanda depende de la tecnología de los procesos de producción o de los hábitos de consumo, en su caso, la disposición a pagar de cada tipo de consumidor depende del precio al que pueda obtener la energía por procedimientos alternativos al de suscribirse al suministro público eléctrico.

45 Consistente en un flujo uniforme, a lo largo de las veinticuatro horas del día y para una determinada estacionalidad, especialmente cuando los saltos no están regulados. 
Dadas las circunstancias en que se fijaban las tarifas, los suministradores gozaban de un amplio grado de control sobre los precios. En general, en los concursos para el otorgamiento de concesiones de suministro participaba un único postor, por lo que, para empezar, la Administración tenía escaso margen para la negociación. El candidato que concurría era el que, con anterioridad, había conseguido los derechos sobre los recursos hidráulicos que le permitían abastecer la plaza al menor coste. En el ámbito en que la Administración local tenía poder de veto, el alumbrado público y domiciliario, la estrategia del municipio se orientaba a minimizar los cargas en servicios públicos $y$, por tanto, aquél tendía a negociar el menor precio posible del suministro para alumbrado público. La compañía de suministro, por su parte, presionaba para que el municipio le aprobara unas tarifas para el suministro domiciliario que le permitieran resarcirse, en la totalidad o en parte, del coste del alumbrado público que, muy probablemente, dados los precedentes, no acabaría cobrando. Respecto al resto de servicios, en la medida en que la normativa sólo insistía en negociar las tarifas de los esenciales, el control de la compañía de suministro era total. Para dichos servicios, el interés del concesionario, a la presentación del proyecto, consistía en proponer unos precios, en concepto de tarifas comerciales e industriales, que fuera lo más alto posible. Cuanto más alta la cota de precio máximo, mayor margen para la negociación con los clientes potenciales. Con el transcurso del tiempo, como se observa para otros países, dicha cota tuvo que irse distanciando de los costes de suministro efectivo, ya que las empresas pudieron beneficiarse de economías de escala y gestión y del progreso de la tecnología del equipo eléctrico.

El sistema de establecimiento de precios, que orientaba tanto la confección de las tarifas oficiales como la fijación de los precios efectivamente cobrados por las compañías de suministro, seguía los principios subyacentes al sistema de tarifas ajustado a la demanda, descrito por Neufeld (1987). Se trataba de ofrecer unos precios ligeramente más bajos que los que tendrían que pagar sus clientes en caso de recurrir a otras opciones energéticas. La publicación de tarifas oficiales no impedía la posibilidad de dar un trato diferente según demandas, por ejemplo entre las destinadas a alumbrado, potencia industrial o tracción ${ }^{46}$. El tipo de tarifas adoptado, que

46 De hecho, en su primera formulación (memoria del año 1905), Hidroeléctrica Ibérica ofrece once tarifas en términos de pesetas por unidad de energía. Para determinar el precio por unidad de energía, cada una de las tarifas ofrecidas tiene en cuenta distintos elementos, como la cantidad contratada al año y su distribución horaria y estacional (y el hecho que dicha distribución la decidiera el cliente o la compañía), la distancia del cliente respecto 
tenían en cuenta el consumo máximo instantáneo (cuyo nivel se denominaba «demanda» al principio de la industria), el consumo total de energía y otras características de la demanda y del tipo de uso, permitía obtener información sobre los costes en que debían incurrir los clientes, si decidían abastacerse con otras formas de energía y, por tanto, resultaba tan eficaz para conseguir discriminar en precios entre distintos consumidores como la negociación individual con cada uno de ellos (Antolín, 1989). Esta política de precios, en su versión más elemental, ya fue utilizada por Edison en la primera empresa de electricidad comercial ${ }^{47}$. Las características de aquellos contratos, y las de otros métodos alternativos de fijación de precios ensayados al principio de la industria, eran bien conocidas por los empresarios eléctricos, ya que se difundían y discutían a través de varias publicaciones periódicas internacionales dedicadas a los problemas técnicos y comerciales del suministro eléctrico.

Un buen ejemplo de los objetivos y del funcionamiento del sistema de tarifas ajustado a la demanda lo tenemos en la política de precios desarrollada por Hidroeléctrica Ibérica desde su creación en 1901. En la primera memoria anual a la Junta de Accionistas sus directivos fueron explícitos acerca de la política de precios que seguiría la empresa. En ella se dice que «... los precios de venta que puede establecer la sociedad se fijarán, como límite máximo de dicho precio, precisamente el mínimo a que hoy se obtiene la fuerza industrial; dicho límite, como antes se dice, es para el caso de las mejores máquinas de vapor, dado el precio actual de los carbones y demás artículos que antes se detallan, 3,75 céntimos de peseta el $C V$ ». «Este precio es el que se fija para sus cálculos la sociedad, mas el que ha de servir como tipo de venta de fuerza será mayor seguramente si, como es de esperar, se emplea en industrias ya establecidas, que obtienen la fuerza a precios muy elevados, y principalmente en los casos en que se trate de instalaciones de alumbrado o tracción eléctrica.» Cuarenta años más tarde dicha estrategia de precios seguía prevaleciendo. En una monografía sobre la industria eléctrica española se afirma que «... cuando no existe monopolio legal de venta de electricidad, tal como sucede en España... el precio de venta de la energía viene fijado por el vendedor a base de los precios de coste, del mayor o menor interés que despierta el producto

a la central, o el uso que se fuera a dar a la electricidad (alumbrado o potencia; dentro de los usos industriales se diferenciaba también según la potencia de los motores a alimentar).

${ }^{47}$ Para determinar el precio de la luz eléctrica, Edison tuvo en cuenta el precio de la luz de gas, y un plus imputable a la mejor calidad y menor riesgo de la eléctrica. 
al consumidor y del riesgo de posibles competencias, siempre dentro del cumplimiento de la legislación eléctrica del país».

Las prácticas de discriminación de precios descritas llevarían a predecir que los precios de la electricidad comercial se hubieran mantenido próximos a los de formas de energía alternativas. En un trabajo anterior, tomando el precio del carbón como indicador de dichas alternativas, y observando ambas series de precios desde 1913, año en que empiezan a estar disponibles, hasta 1929 (último año seleccionado, para excluir las perturbaciones relacionadas con la depresión de los años treinta) he podido comprobar que mientras que en los EEUU los precios del carbón y el de la electricidad, en términos absolutos, divergen fuertemente, en España mantienen trayectorias mucho más cercanas. Esta circunstancia es incluso más evidente en el País Vasco, donde mayor es el poder de monopolio de la empresa suministradora. Esta escasa divergencia es todavía más notable en términos de precios relativos, y contrasta con la de los mismos bienes en EEUU, país que me interesa como comparación porque, en él, las prácticas de discriminación de precios resultaron inoperantes debido a la competencia entre las compañías de suministro y, allí donde se establecieron monopolios, se vieron restringidas por la regulación de precios vigente desde principios de siglo ${ }^{48}$. El escaso distanciamiento entre el precio de la electricidad y el del carbón representa un menor estímulo relativo hacia la electrificación en España, mientras que el escaso distanciamiento entre el precio de la electricidad y los salarios contribuye a explicar el bajo nivel de mecanización alcanzado en los procesos industriales españoles ${ }^{49}$.

La tabla 3 muestra la relación entre consumo de electricidad y renta per cápita en varios países en años significativos. España tuvo un buen comienzo en términos de consumo. En 1900 estaba por encima de Italia, Francia o el RU. Ésta fue la etapa de las grandes esperanzas, en la que numerosas iniciativas para suministros individuales (autoproductores) o colectivos (pequeñas compañías de suministro) se aprestaron a abastecer

${ }_{48}$ La competencia entre suministradoras se vio favorecida en Estados Unidos, porque la fuente de energía primaria dominante en disponibilidad y precio fue el carbón. En el abastecimiento del carbón no se dan las barreras a la entrada propias del acceso a los recursos hidráulicos, y las exigencias financieras para infraestructuras de producción y suministro son menos costosas y discontinuas. La regulación sobre precios se impuso desde los primeros años del siglo.

${ }_{49}$ El análisis comparativo en los precios de energía entre EEUU y España en Antolín (1988) suscitó años más tarde una polémica que se recoge en la Revista de Historia Económica, núm. 3, otoño 1990 
TABLA 3

Crecimiento económico y consumo de electricidad

\begin{tabular}{|c|c|c|c|c|c|c|}
\hline Año & España & Francia & Alemania & Italia & $U K$ & USA \\
\hline PNB & 1.873 & 2.838 & 2.688 & 1.907 & 4.546 & 4.394 \\
\hline Kwh ...................... & 10,2 & 7,59 & 31,8 & 3,3 & 5,2 & 64,9 \\
\hline PNB & 2.091 & 3.436 & 3.288 & 2.472 & 4.980 & 5.694 \\
\hline Kwh ...................... & 24,6 & 45 & 119 & 55 & 54 & 272,5 \\
\hline PNB & 2.768 & 4.668 & 3.713 & 3.274 & 5.200 & 7.410 \\
\hline Kwh ....................... & 104,8 & 378 & 473 & 243 & 371 & 958,7 \\
\hline PNB & 2.711 & 4.051 & 3.774 & 3.469 & 5.480 & 5.807 \\
\hline 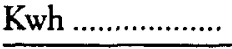 & 129,4 & 495 & 807 & 350 & 711 & $1.092,2$ \\
\hline PNB.. & 2.254 & 3.280 & 5.528 & 3.694 & 7.070 & 8.698 \\
\hline 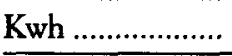 & 104,0 & 284,4 & 902 & 398,6 & 621,9 & $1.361,9$ \\
\hline PNB $\ldots \ldots \ldots \ldots \ldots$ & 2.332 & 2.550 & 4.303 & 2.301 & 6.668 & 12.374 \\
\hline 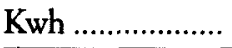 & 170,3 & 462,7 & 386,9 & 272,9 & 786,3 & $1.938,9$ \\
\hline
\end{tabular}

Las cifras sobre PNB se refieren al PNB per cápita en - 1990 US \$- Geary-Khamis. Las cifras sobre electricidad son kwh per cápita.

Fuentes: Prados de la Escosura (1995), «Spain's Gross Domestic product, 1850-1993: Quantitative conjetures», Universidad Carlos III de Madrid, Working Papers, 95-05.

Etemad \& J. Luciani (1991).

los consumos que el vapor, excesivamente caro, no había satisfecho. Pero después de esta fecha cayó por debajo de los niveles de estos países, incluyendo Italia, con similar renta per cápita y recursos energéticos, y en vísperas de la Guerra Civil no había conseguido recuperarse de dicha caída. Ésta es la etapa en que, gracias al avance tecnológico en la transmisión de electricidad a largas distancias, se consiguió aprovechar las mejores dotaciones en recursos hidráulicos, pero cuya gestión a través de monopolios privados locales sin regular retuvo gran parte de los beneficios sociales de la nueva tecnología en provecho del sector productor.

\section{UNA APROXIMACIÓN A LOS RESULTADOS OBTENIDOS DE LA GESTIÓN DEL SECTOR ELÉCTRICO}

A modo de conclusión, me centraré ahora en la valoración de los resultados obtenidos por la industria de suministro eléctrico al finalizar el perío- 
do de implantación y primer desarrollo. En una primera aproximación revisaré los aspectos más inmediatos y evidentes, los de producción, precios y beneficios y, en una segunda aproximación, los aspectos más genéricos e imponderables; la eficiencia, en términos de costes y asignación de recursos, la justicia distributiva y el crecimiento económico.

Sin menospreciar los factores de todo tipo que intervienen en la gestión de los recursos eléctricos, intentaré destacar aquellos aspectos que fueron consecuencia de opciones básicas tomadas por agentes públicos y privados ${ }^{50}$. Opciones que podemos caracterizar por la colaboración incondicional, en la práctica, entre la Administración pública y las grandes hidroeléctricas, y la maximización a corto plazo por parte de estas últimas.

En páginas anteriores expuse las características y la lógica de la estrategia de producción y precios desarrollada por las grandes empresas para rentabilizar el capital en circunstancias ciertamente complejas. Consistía en evitar la sobrecapacidad, condicionando la expansión de la inversión a la existencia de una demanda dispuesta a absorber la nueva capacidad instalada, y en maximizar ingresos fijando los precios a pagar por cada tipo de cliente al límite de su disponibilidad a pagar. Las consecuencias esperadas de esta estrategia de mínimo riesgo, propia de actividades que requieren fuertes inversiones en capital fijo específico y que se benefician de posiciones de monopolio natural, cuando no está regulada para servir al interés general, son que el productor retiene gran parte de los beneficios generados. Así, ya vimos que los precios pagados por la electricidad se distanciaban muy poco de los pagados por el uso del carbón, y que los usuarios que conseguían beneficiarse del suministro eran sólo un subconjunto de usuarios potenciales, cuya demanda agregada coincidiese con el flujo de producción obtenido con las instalaciones actuando a plena capacidad. En términos de calidad, el consumidor español no fue el mejor servido. A diferencia de otros países, y en el período tratado, la normativa eléctrica española no incluye disposiciones, ni sistemas de control o penalización, para asegurar la fiabilidad y calidad del servicio. Por ello, las compañías eléctricas tuvieron escasos incentivos para fijarse estándares e instrumentar los medios (equipos de control y reserva u otros) para alcanzarlos.

Disponemos de escasa información respecto a la rentabilidad obtenida por los capitales invertidos en las grandes compañías del sector. Para el conjunto de las 30 mayores empresas, Gari y Santasusana (1929) calculan

${ }^{50}$ Para una discusión sobre los distintos aspectos que intervienen en la gestión de los recursos eléctricos, ver Antolín (1997). 
una rentabilidad del 6,9 por 100 para el año 1927. De mi estudio de los resultados de Hidroeléctrica Ibérica, obtengo un rendimiento de 7,7 por 100 como media en el período 1904-1943. Dicha cifra, obtenida de la diferencia entre ingresos y costes netos es sólo un indicador del beneficio, puesto que no permite ponderar la cuantía de la reinversión.

Por lo que respecta a la eficiencia, en términos de costes y asignación de recursos, la gestión de las grandes hidroeléctricas muestra algunos aspectos claramente positivos. El control del mercado asociado al status de monopolio local les permite producir a costes medios muy bajos, gracias a las economías de escala y a la alta tasa de utilización de las instalaciones de que disfrutan. A medio plazo, no obstante, la incuestionable reserva del mecado les tuvo que llevar a negligir el objetivo de crecimiento e innovación tecnológica, aspectos básicos de la eficiencia dinámica. En el otro aspecto considerado, la asignación de recursos, el balance es netamente positivo. La política de discriminación de precios utilizada lleva a extender la producción hasta el punto en el que el precio pagado por el último suscriptor se iguala al coste marginal. Simultáneamente, desde el punto de vista de la asignación de la producción, el criterio de disposición a pagar en que se basaba el sistema de precios lleva a distribuir la electricidad hacia los usos que obtienen un mayor provecho de esta forma de energía.

Las consecuencias sobre justicia distributiva y crecimiento económico estuvieron directamente relacionadas con la escasa capacidad negociadora y la permisividad de facto de la Administración local ante las propuestas de las compañías que concurrían a las subastas de concesiones de suministro, en lo referido a precios, duración de los contratos y ámbitos de regulación. Esta permisividad vino forzada en muchos casos por la presencia de un único postor. La aceptación de políticas de precios basadas en la disposición a pagar de los consumidores permitió que los abastecedores que operaban monopolios locales se apropiaran del excedente del consumidor. En la distribución de la nueva riqueza generada por la electricidad, la parte beneficiada fue, por tanto, la de las compañías de suministro.

Entre las contribuciones potenciales de la electricidad al crecimiento económico se pueden diferenciar dos aportaciones básicas: el aumento de la cantidad de energía disponible, y la mejora en la productividad de los procesos de producción. Ambas aportaciones fueron moderadas en el caso español, y ello debido a circunstancias que afectaron tanto a la demanda como a la oferta. Dada la posibilidad de reutilización de la energía hidráulica, los aprovechamientos creados representaron un incremento neto de energía disponible en España. La cuantía de energía hidroeléctrica gene- 
rada, que como vimos en la tabla 3 tuvo un inicio espectacular aunque muy pronto quedó rezagada en términos relativos a otros países, se vio condicionada, de forma genérica, por la capacidad de expansión de la economía española, en la que intervienen muchos factores y, de forma más específica, por el precio a pagar por la electricidad. En este último aspecto, creo que la política de precios consistente en mantener el precio de la electricidad a escasa distancia del de las energías alternativas restó incentivos a su adopción (especialmente alli donde implicase desembolsos por adquirir nuevos equipos o instalaciones) y a la introducción de procesos más intensivos en energía.

Los estudios realizados para el conjunto de países industriales demuestran que la contribución más sobresaliente de la electricidad consiste en mejorar la productividad de los procesos industriales mediante la introducción de tecnologías especificas a dicha forma de energía. En el caso español, los datos disponibles sobre la moderación del consumo tanto absoluto como relativamente a otras formas de energía, el estancamiento en la productividad industrial y la nula progresión de la eficiencia en el uso de la energía eléctrica, nos permiten afirmar que las mejoras en la productividad debieron ser anecdóticas. Algunos casos en que sí hubo incrementos importantes de productividad como, por ejemplo, en el procesado de mineral de hierro vizcaíno en la primera década de siglo, apuntan a las circunstancias que los propiciaban. En este caso, se trataba de un producto para el que existía un mercado exterior en expansión altamente remunerativo, y para cuyo procesado, calcinación y lavado existían nuevas tecnologías que requerían el uso de electricidad ${ }^{51}$. Las circunstancias del sector industrial español resultaron escasamente incentivadoras para la adopción de una tecnología de punta, que exigía la incorporación y renovación periódica de equipos costosos con una capacidad de producción en rápida expansión. Organizados en estructuras oligopolistas, especialmente en los sectores más intensivos en energía, los industriales se fijaron objetivos conservadores, consistentes en abastecer el mercado interior, con una capacidad de expansión limitada, y protegido frente a la competencia exterior [Fraile (1991)].

"1 Como observaba en un trabajo anterior, el abastecimiento de las instalaciones mineras de la margen derecha de la ría de Bilbao fueron el objetivo preferente y la principal fuente de clientes para Hidroeléctrica Ibérica en los primeros años de gestión [Ántolín (1996)].

Francesca Antolín Fargas. Catedrática de Escuela Universitaria en la Universidad de Barcelona. Es licenciada en Ciencias Económicas por la Universidad Complutense, doctora por la Universidad del País Vasco y Master of Arts por Northwestern University. Ha sido también profesora en la UPV y en la UAB. Sus investigaciones sobre recursos hidráulicos, industria eléctrica y otros servicios públicos exploran las relaciones entre dotaciones naturales, marco legal y estrategia empresarial en la configuración de sectores clave de la economía. 


\section{BIBLIOGRAFÍA}

ANTOLí, F. (1988), «Electricidad y crecimiento económico. Los inicios de la electricidad en España», Revista de Historia Económica, núm. 3.

- (1989), «Un servicio público con escasa intervención. Los primeros cuarenta años de electricidad en España», Economia Industrial, enero.

- (1990), «Electricidad y crecimiento económico. Una hipótesis de investigación», Revista de Historia Económica, núm. 3.

- (1991), «Las empresas de servicios públicos municipales», en MARTíN ACEÑA, P., y Comín, F., Historia de la empresa pública en España, Espasa-Calpe, Madrid.

- (1992), «Public policy in the development of the Spanish electric utility industry». Presentado en «A Century of Industrial Policy in Europe», Oxford, diciembre.

- (1996), «Hidroeléctrica Ibérica y la electrificación del País Vasco», en MarTíN ACeña, P., y Comín, F. (eds.), La empresa en la Historia de España, Civitas, Madrid.

- (1997), «Dotaciones y gestión de los recursos energéticos en el desarrollo económico de España», Papeles de Economia Española, núm. 73

ARRúe, M. (1935), Desarrollo y perspectiva del consumo de energía eléctrica para luz, Madrid.

Aubanell, A. (1992), «La competencia en la distribución de electricidad en Madrid, 1890-1913», Revista de Historia Industrial.

Banco de Vizcaya, Memorias (años 1956 y 1963).

CARRERAS, A. (1983), La producció industrial espanyola $i$ italiana desde mitjan segle XIX fins a l'actualitat (Tesis doctoral).

- (1989): «La industria: atraso y modernización», en NADAL, J., et al. (eds.), La economia española en el siglo XX, Ariel, Barcelona.

Cayón García, F. (1997), «Un análisis del sector eléctrico en Madrid a través de las empresas Hidroeléctrica Española, Electra Madrid y Unión Eléctrica Madrileña», Fundación Empresa Pública, Programa de Historia Económica (documento de trabajo).

Coll, S., y SudRía, C. (1987), El carbón en España, 1770-1961, Turner.

CREW y KLEINDORFER (1986), The economics of public utility regulation, Macmillan Press.

DARMSTADTER, J., et al. (1971), Energy in the world economy. A statistical review of trends in output, trade and consumption since 1925, The John Hopkins Press.

Díaz-Caneja, F. (1985): «Regulación administrativa del sector eléctrico», Economía Industrial, Madrid.

Emmons, W. M. (1989), Private and Public Responses to Market Failure in the US Electric Power Industry, 1882-1942 (Tesis Doctoral, Harvard University).

- (1992), «Frenklin D. Roosevelt, Electric Utilities, and the Power of Competition», The Journal of Economic History, vol. 54.

Etemand, B., y Luciani, J. (1991), World Energy Production, 1800-1985, Droz. ForEman-PECK, J., y WATERSON, M. (1985), «The comparative efficiency of public and private enterprise in Britain: electricity generation between the World Wars», The Economic Journal, vol. 95. 
FRAILE, P. (1991), Industrialización y grupos de presión. La economía politica de la protección en España, 1900-1950, Alianza Editorial, Madrid.

Fundación Sevillana de Electricidad (1994), Compañia Sevillana de Eléctricidad. Cien años de Historia, Sevilla.

Garcta de la Infanta, J. M. (1986), Primeros pasos de la luz eléctrica en Madrid y otros acontecimientos, Ediciones Fondo Natural, Madrid.

GaRrues IsURzUN, J. (1993), «La formación del mercado eléctrico vasconavarro e Hidroeléctrica Ibérica» (documento de trabajo).

- (1997), Empresas y empresarios en Navarra. La industria eléctrica, 1888-1986, Gobierno de Navarra, Pamplona.

Germán, L. (ed.) (1990), ERZ (1919-1990). El desarrollo del sector eléctrico en Aragón, Instituto Fernando el Católico y Eléctricas Reunidas de Zaragoza, Zaragoza.

Hidroeléctrica Ibérica, Memorias del Consejo de Administración (varios años).

Hughes, Th. (1983), Networks of Power. Electrification on Western Society, 1880-1930, The John Hopkins University Press.

Joskow, P. L., y Schmalensee, R. (1985), Markets for Power. An Analysis of Electrical Utility Deregulation, The MIT Press.

LANDES, D. (1969), The Unbound Prometheus, Cambridge UP, Cambridge.

LÓPEz Mayor, V. (1988), Legislación eléctrica básica, Tecnos (Biblioteca de textos legales).

Machimbarrena, V. (1941), Orbegozo. Historia de un ingeniero, A. G. Faure, Madrid.

Maluquer de Motes, J. (1983): «L'electricitat», en NADAL, J., et. al. (1983), Producció $i$ consum d'energia en el creixement econòmic modern: el cas català.

- (1992), «Los pioneros de la segunda revolución industrial en España. La sociedad Española de Electricidad (1881-1894)», Revista de Historia Industrial.

MARTÍN-ACENAA, P., y Comf́, P. (1991), INI. 50 años de industrialización en España, Espasa Calpe.

Martínez LÓPEZ, J. L. (1991), «El sector eléctrico en España», en «Presente y futuro del sector eléctrico», Revista del Instituto de Estudios Económicos, núm. 4.

MEYER, R. J. (1975), «Public owner versus privately owned utilities: A policy choice», The Review of Economics and Statistics, vol. LVII.

MilWARD, R. (1982), «The compartive performance of public and private owership», en The Mixed Economy, E. Roll (ed.), Macmillan.

Muñoz Linares, C. (1954): El monopolio en la industria eléctrica, Aguilar, Madrid.

Muñoz MACHADO, S., y BAÑo LEÓN, J. M. (1991), «La intervención administrativa en el sector eléctrico: exigencias constitucionales y comunitarias frente a una futura reforma legislativa», en «Presente y futuro del sector eléctrico», Revista del Instituto de Estudios Económicos, núm. 4.

Nadal, J., et. al. (1983), Producció $i$ consum d'energia en el creixement econòmic modern: el cas català (inédito)

NeufelD, J. L., «Price Discrimination and the Adoption of the Electricity Demand Charge», Joumal of Economic History, vol. XLVII, núm. 3.

Núñez-Romero Balmas, G. (1993), La Sevillana de Electricidad (1894-1930) y la promoción multinacional en el sector electrotécnico, Ediciones Némesis, Granada.

OCDE (1983), «Perspectives économiques de l'OCDE», «Energetic Balances» $\mathrm{y}$ «Main Economic Indicators». 
Pescatrice, D. R., y Trapani, J. M. (1980), «The performance and objetives of public utilities operating in the United States», Journal of Public Economics, vol. 13.

Prados de la Escosura, L. (1992), «Real GDP in Spain», Documentos de Trabajo, Dirección General de Planificación, Ministerio de Economía y Hacienda.

- (1995), «Spain's Gross Domestic product, 1850-1993: Quantitative conjectures», Universidad Carlos III de Madrid, Working Papers, 95-05.

Sintes Olives, F., y Vidal BuRdils, F. (1933), La industria eléctrica en España, Montaner y Simón, Barcelona.

STOFFAES, C. (ed.) (1994), Entre monopole et concurrence. La régulation de l'énergie en perspective historique, Editions PAU.

Sudrià, C. (1987), «Un factor determinante: la energía», en NADAL, J.; CARRERAS, A., y SUDRid, C. (comp.), La economía española en el siglo XX. Una perspectiva bistórica, Ariel.

- (1990), «La electricidad en España antes de la Guerra Civil: una réplica», Revista de Historia Económica, núm. 3.

- (1990), «Puntualizaciones a la respuesta de Francesca Antolín», Revista de Historia Económica, núm. 3.

- (1997), «La restricción energética al desarrollo económico de España», Papeles de Economía Española, núm. 73.

TEDDE DE LORCA, P. (1987), «Hidroeléctrica Española. Una contribución empresarial al proceso de crecimiento económico», en Hidroeléctrica Española. 75 aniversario, HIDROLA.

Uriarte, E. (1949), «La energía eléctrica en España», Agenda financiera, 1945, Banco de Bilbao.

VIDAL BurdLs, F. (1940), Economia eléctrica de España, Barcelona. 